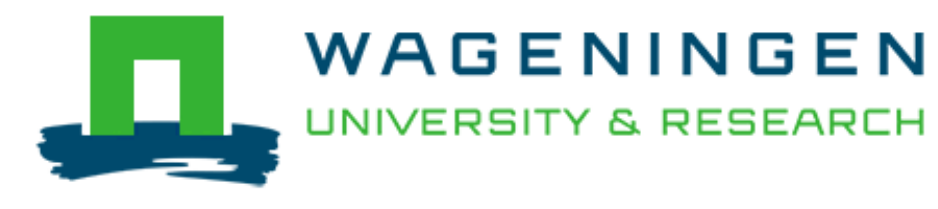

\title{
Effects of a mixture of Bacillus amyloliquefaciens and Bacillus subtilis on the performance of growing-finishing pigs
}

van der Peet-Schwering, C. M. C., Verheijen, R., Jørgensen, L., \& Raff, L.

This is a "Post-Print" accepted manuscript, which has been Published in "Animal Feed Science and Technology"

This version is distributed under a non-commercial no derivatives Creative Commons (c) (1) @ $\Theta$ (CC-BY-NC-ND) user license, which permits use, distribution, and reproduction in any medium, provided the original work is properly cited and not used for commercial purposes. Further, the restriction applies that if you remix, transform, or build upon the material, you may not distribute the modified material.

Please cite this publication as follows:

van der Peet-Schwering, C. M. C., Verheijen, R., Jørgensen, L., \& Raff, L. (2020). Effects of a mixture of Bacillus amyloliquefaciens and Bacillus subtilis on the performance of growing-finishing pigs. Animal Feed Science and Technology, 261, [114409]. https://doi.org/10.1016/j.anifeedsci.2020.114409

You can download the published version at:

https://doi.org/10.1016/j.anifeedsci.2020.114409 
35 Submitted to Animal Feed Science and Technology in May 2019
Effects of a mixture of Bacillus amyloliquefaciens and Bacillus subtilis on the performance of growing-finishing pigs
C.M.C. van der Peet-Schwering ${ }^{\mathrm{a},{ }^{*}}$, R. Verheijen ${ }^{\mathrm{a}}$, L. Jørgensen ${ }^{\mathrm{b}}$, L. Raff ${ }^{\mathrm{b}}$

${ }^{a}$ Wageningen University and Research, Wageningen Livestock Research, P.B. 338, 6700 AH, Wageningen, The Netherlands

${ }^{b}$ Chr. Hansen A/S, Bøge Allé 10-12, DK-2970 Hørsholm, Denmark
* Corresponding author. Tel: +31 317 480730; E-mail address: carola.vanderpeet@wur.nl

36

37 


\section{Abstract}

The study was conducted to determine the effects of a Bacillus-based probiotic (mixture of spores of Bacillus amyloliquefaciens (DSM 25840) and Bacillus subtilis (DSM 32324) supplementation on growth performance and health of growing-finishing (GF) pigs. A total of 576 GF pigs with initial body weight $(\mathrm{BW})$ of $23.2 \pm 2.95 \mathrm{~kg}$ were allotted to one of two treatments (control diet and probiotic diet). Pigs were blocked by litter origin, BW and sex and allotted to 24 mixed-sex pens ( 6 entire males and 6 females per pen) per treatment. The GF pigs were fed pelleted diets containing 0 (control diet) or $400 \mathrm{mg} / \mathrm{kg}\left(6 \times 10^{8} \mathrm{CFU}\right.$ per $\mathrm{kg}$ feed; confirmed by analysis) of the Bacillus-based probiotic. The diets were supplied ad libitum as dry feed. Pigs were followed till day 102 after the start of the study. During the grower phase (1-35 days), probiotic supplementation tended to improve the feed conversion ratio $(\mathrm{FCR})(P=0.09)$. During the finisher phase (35-102 days), probiotic supplementation significantly improved FCR $(P=0.03)$ and tended to increase the average daily gain $(\mathrm{ADG})(P=0.09)$. During the overall period $(1-102$ days), probiotic supplementation significantly improved FCR $(P=0.01)$. Probiotic supplementation did not affect the number of culled and veterinary treated pigs. The number of treatments due to ileitis (an infection with Lawsonia intracellularis), however, tended to be lower in the probiotic group ( 7 vs $16 ; P=0.07$ ). Most pigs showed normal faecal consistency in the grower phase and the mean pen faecal score during the grower phase was similar in the control group and the probiotic group. In conclusion, feeding GF pigs diets supplemented with $400 \mathrm{mg} / \mathrm{kg}$ of a Bacillus-based probiotic containing a mixture of viable spores (confirmed by analysis before used in this trial) of two specific strains of Bacillus amyloliquefaciens and Bacillus subtilis improved the FCR of the GF pigs during the overall fattening period. Moreover, it tended to decrease the number of veterinary treatments due to ileitis. 
62 Keywords: Bacillus amyloliquefaciens, Bacillus subtilis, growing-finishing pigs, performance

Abbreviations: AA, amino acids; ADG, average daily gain; ADFI, average daily feed intake; AID, apparent ileal digestibility; ATTD, apparent total tract digestibility; BW, body weight; DE, digestible energy; DM, dry matter; FCR, feed conversion ratio; GF, growing-finishing pigs; HBW, heavy body weight; LBW, light body weight; MBW, medium body weight; N, nitrogen

\section{Introduction}

Since the ban of antibiotics as growth promoters in the European Union in 2006, there has been an increased interest in using probiotics to support health and growth performance of pigs (Blavi et al., 2019). It has been extensively documented that probiotics can reduce digestive disorders and improve performance parameters (Ahasan et al., 2015; Bajagai et al., 2016). Bacillus spp. are commonly used as probiotics in animal feed (Larsen et al., 2014). Addition of Bacillus-based probiotics to the diet may improve feed efficiency and/or average daily gain (ADG) of growingfinishing (GF) pigs (Chen et al., 2005; Chen et al., 2006; Jørgensen et al., 2016; Bouwhuis et al., 2017). However, the effect of Bacillus-based probiotics on performance of pigs has been characterized as being inconsistent and with low reproducibility from farm to farm (Barba-Vidal et al., 2018). Larsen et al. (2014) characterized 245 bacterial isolates of Bacillus strains and concluded that isolates from Bacillus amyloliquefaciens, Bacillus subtilis, and Bacillus mojavensis showed the best overall characteristics in terms of heat resistance of spores, inhibitory activity against pathogenic bacteria and antibiotic resistance and, therefore, potential for usage as probiotic additives in feed. Blavi et al. (2019) tested the effect of Bacillus amyloliquefaciens (DSM 25840) and Bacillus subtilis (DSM 25841) on the digestibility of energy, protein and amino acids (AA) in 
84 growing pigs. Addition of Bacillus amyloliquefaciens to diets increased the apparent ileal 85 digestibility (AID) of some AA compared with the control diet, whereas addition of Bacillus

86

87 subtilis increased digestible energy (DE) of the diet. It can be suggested that supplementation of diets with a mix of Bacillus amyloliquefaciens and Bacillus subtilis may result in improved performance of GF pigs because of an improved utilization of both AA and energy. Jørgensen et al. (2016) investigated the effects of a mix of Bacillus subtilis and Bacillus licheniformis on the growth performance and apparent total tract digestibility (ATTD) of wean-to finish pigs. They concluded that supplementation of this mix improved ADG, feed conversion ratio (FCR) and ATTD of nutrients in pigs. Information about effects of a mix of Bacillus amyloliquefaciens and Bacillus subtilis on performance of GF pigs, however, is limited.

Therefore, the objective of this study was to study the effects of a Bacillus-based probiotic (mixture of viable spores of Bacillus amyloliquefaciens (DSM 25840) and Bacillus subtilis (DSM 32324)) on growth performance and health of GF pigs.

\section{Materials and methods}

The experiment was conducted at the Swine Innovation Center Sterksel (Sterksel, the Netherlands) from Wageningen Livestock Research (Wageningen, The Netherlands). The farm housing and husbandry were representative of EU farming conditions and met relevant ethical, hygienic and animal welfare requirements. Animals in this study were raised and treated according to Directive 2010/63/EU of 22 September 2010 (European Commission, 2010) and according to the recommendation of the European Commission 2007/526/CE (European Commission, 2007) covering the accommodation and care of animals used for experimental and other scientific 
106 purposes. The Institutional Animal Care and Use Committee of Wageningen Livestock Research

107 approved the experimental protocol.

108

109

110

111

112

113

114

115

116

117

118

119

120

121

122

123

124

125

126

127

128

\subsection{Animals, housing and experimental design}

A total of 576 GF pigs (Large White boar x (York x Dutch Landrace) sow), average initial BW $23.2 \pm 2.95 \mathrm{~kg}$ and average initial age $63 \pm 0.6$ days, were allotted to two treatments (Control diet and Probiotic diet) in two batches of 288 GF pigs each with three weeks in between. Pigs were balanced for litter origin, BW and sex and allocated to 24 mixed-sex pens (replicates) per treatment (12 mixed-sex pens/replicates per treatment per batch). Body weight was balanced by sorting pigs into blocks of light (L), medium (M) and heavy $(\mathrm{H}) \mathrm{BW}$, which were then allocated to $\mathrm{L}, \mathrm{M}$ and $\mathrm{H}$ pens, then adjusted to equalize pen replicates for gender ( 6 males and 6 females per pen). Two pens in each block were then randomly allotted to the two experimental treatments. Pigs were housed in four fattening rooms. Each fattening room had 12 pens measuring $5 \mathrm{~m} \mathrm{x} 2.5 \mathrm{~m}\left(1 \mathrm{~m}^{2}\right.$ per pig). Pen walls were partly open (at the back of the pens). To minimize cross-contamination, all six pens at one side from the aisle were allotted to the same treatment. The six pens at the other side from the aisle were allotted to the other treatment. Pigs were followed till day 102 after the start of the study. Environmental conditions, temperature and ventilation rate in the fattening rooms were automatically controlled and appropriate for the stage of the pigs.

\subsection{Diets and feeding}

Pigs were fed diets containing 0 (control group) or $400 \mathrm{mg} / \mathrm{kg}\left(6 \times 10^{8} \mathrm{CFU}\right.$ per $\mathrm{kg}$ feed) of the Bacillus-based probiotic. The probiotic was a mixture of viable spores of Bacillus amyloliquefaciens (DSM 25840) and Bacillus subtilis (DSM 32324) at a minimum concentration of $1.5 \times 10^{9} \mathrm{CFU} / \mathrm{g}$ and was produced by Chr. Hansen A/S (Hørsholm, Denmark). As the Bacillusbased probiotic was supplied in $\mathrm{CaCO}_{3}$ base, $400 \mathrm{mg} / \mathrm{kg} \mathrm{CaCO}_{3}$ in the control diets was 
129 exchanged with $400 \mathrm{mg} / \mathrm{kg}$ of the Bacillus-based probiotic. Before and in-between production of

130 the diets a cleaning diet (cereal) was passed through the production line to minimize cross-

131 contamination. To ensure homogeneous diets, 800 gram of the Bacillus-based probiotic was mixed

132 with $5 \mathrm{~kg}$ of the basal diet before mixing in $2,000 \mathrm{~kg}$ batches of the diet. The GF pigs were fed a

133 grower diet during the first five weeks and then a finisher diet till the end of the trial. The

134 composition of the control diets is presented in Table 1. All diets were formulated with a low level

135 of copper and no added organic acids, polysaccharidases, yeasts or probiotics other than the

136 probiotic to be tested in the trial. All nutrients were supplied at normal concentrations, not

137 exceeding EU maximum permitted concentrations for trace minerals or vitamins. The diets met

138 Centraal Veevoederbureau (2012) nutrient recommendations for GF pigs. Pigs had ad libitum

139 access to the pelleted diets and to drinking water. The diets were fed in a dry feed hopper with two

140 feeding places.

$141 \quad 2.3$. Measurements

142 Pigs were weighed individually at the start of the trial and at days 35 and 102 (end of the trial).

143 Total feed intake per pen was measured at the end of each feeding phase. Average daily gain, 144 average daily feed intake (ADFI) and FCR were calculated from the start till the end of the trial 145 and in both feeding phases. The number of pigs treated with antibiotics (Engemycine ${ }^{\circledR} 10 \%(4 \mathrm{ml}$ 146 per $50 \mathrm{~kg} \mathrm{BW})$, MSD Animal Health, Boxmeer, The Netherlands; Penject 30 (1 ml per $10 \mathrm{~kg} \mathrm{BW})$, 147 Dopharma, Raamsdonkveer, The Netherlands) and the number of culled pigs were recorded. In 148 general, pigs were treated for 3-5 consecutive days per treatment. Lame pigs were treated with 149 Penject 30. The animal caretakers had years of experience with diagnosing ileitis caused by 150 Lawsonia intracellularis (grey/black diarrhea and failure to grow) and treatments were based on 151 their experience. Pigs with ileitis were treated with Engemycine ${ }^{\circledR} 10 \%$. Faecal scores were 
152 performed weekly during the grower phase. In each pen the number of pigs with normal faeces

$153($ score $=0)$, pasty faeces $($ score $=1)$ and watery faeces $($ score $=2)$ was scored visually by the same

154 person across the treatment groups (Van Nieuwamerongen et al., 2017). The mean score was

155 calculated per pen per week. Thereafter, the mean score per pen during the five weeks was calculated.

156 Diets were analysed for moisture by drying at $103^{\circ} \mathrm{C}$ (European Commission, 2009), crude protein

157 by using the Kjeldahl method (European Commission, 2009), ash by combustion to a constant

158 weight at $550{ }^{\circ} \mathrm{C}$ (European Commission, 2009), crude fat after hydrolysis (European

159 Commission, 2009 ), $\mathrm{Cu}$ (only the starter diet; NEN-EN 15510, 2017) and the number of CFU/kg

160 diet of the added Bacillus-based probiotic (NEN-EN-15784, 2009).

161 2.4. Statistical Analysis

162 Performance parameters (BW, ADG, ADFI, FCR) and mean faecal scores per week (weeks 1

163 to 5) were analysed with pen as experimental unit using a two-way ANOVA procedure (GenStat,

164 2018). The model used was:

$165 \mathrm{Y}=\mu+$ batch + block within batch $+\operatorname{diet}+\varepsilon$

166 where:

$167 \mathrm{Y}=$ dependent variable, $\mu=$ population mean, batch $=$ batch effect $(1,2)$, block $=$ block effect $(1$

168 to 24$)$, diet $=$ effect of dietary treatment $(1,2)$ and $\varepsilon=$ residual error.

169 Data are presented as least square means. The number of culled pigs and pigs treated with 170 antibiotics were analysed using the Chi-square test of SAS 9.3 (2011). Probability values of $P \leq$ 1710.05 were considered significant, whereas $0.05<P \leq 0.10$ was considered as a tendency. 

$187 \quad$ ADG and ADFI.

The levels of crude protein, crude fat, ash and $\mathrm{Cu}$ in the grower and finisher diet were as expected (Table 1). The CFU analysis confirmed the target CFU per kg of diet (less than $1.0 \times 10^{8}$ $\mathrm{CFU} / \mathrm{kg}$ diet in the control diets and $4.37 \times 10^{8}$ and $5.25 \times 10^{8} \mathrm{CFU} / \mathrm{kg}$ diet in the grower and finisher diets with Bacillus-based probiotics, respectively).

\subsection{Growth performance}

In the probiotic group, one pen was deleted from the results because this pen was an outlier (the daily gain of the pigs in this pen was more than two time the standard deviation lower than the mean daily gain of the pigs in the probiotic group). During the grower phase (1-35 days), probiotic supplementation tended to improve FCR $(P=0.09)$, but it did not affect ADG and ADFI (Table 2). During the finisher phase (36-102 days), probiotic supplementation significantly improved FCR $(P=0.03)$ and tended to increase ADG $(P=0.09)$. During the overall period (1102 days), probiotic supplementation significantly improved FCR $(P=0.01)$, but it did not affect

\subsection{Health and faecal scores}

Probiotic supplementation did not affect the number of culled and individually veterinary treated pigs (Table 3). Pigs were only individually veterinary treated and not on pen level. The number of treatments with antibiotics did not differ between the control and the probiotic group $(P=0.12)$. The number of treatments due to ileitis caused by Lawsonia intracellularis, however, tended to be lower in the probiotic group ( $7 \mathrm{vs} 16 ; P=0.07)$. The mean number of treatment days (as percentage of total number of trial days) was not affected by probiotic supplementation. Mean pen faecal score during the grower phase was within normal range and similar in the control group and the probiotic group (Table 3). 


\section{Discussion}

The Bacillus-based probiotic (mix of Bacillus amyloliquefaciens and Bacillus subtilis) improved FCR during both the grower and finisher period and the overall fattening period and tended to increase ADG during the finisher phase. In weaned piglets, a mix of Bacillus amyloliquefaciens and Bacillus subtilis also improved FCR and ADG (Cai et al., 2015) or only FCR (Jaworski et al., 2017). It hasn't been possible, however, to locate any published studies in which the effect of a mix of Bacillus amyloliquefaciens and Bacillus subtilis on the performance of GF pigs was studied. There are a few studies in which the separate effect of Bacillus amyloliquefaciens was tested in GF pigs. Bouwhuis et al. (2017) reported an improved FCR during the overall fattening period in GF pigs that were fed a diet with Bacillus amyloliquefaciens (DSM 25840). A positive effect of Bacillus amyloliquefaciens on nutrient digestibility might explain the improved FCR in our study and in the study of Bouwhuis et al. (2017). Bacillus amyloliquefaciens produce $\alpha$-amylase (Gangadharan et al., 2008), cellulase (Lee et al., 2008) and proteases (Gould et al., 1975), which can improve the digestion of nutrients. In both growing and finishing pigs, Blavi et al. (2019) showed a greater AID of total indispensable, total dispensable and total AA in the diet supplemented with Bacillus amyloliquefaciens (DSM 25840) compared to the control diet. The improved AID of AA in both growing and finishing pigs might explain the improved FCR during the overall fattening period.

Improvement in FCR in GF pigs as a result of Bacillus supplementation may also be due to the impact of Bacillus on pig health through beneficial immune modulation (Davis et al., 2008), competitive exclusion of gastrointestinal pathogens, and secretion of the antimicrobial compounds that suppress the growth of harmful bacteria (Ji et al., 2013; Li et al., 2015). In our study, the percentage of pigs treated with antibiotics (11.5 vs $8.7 \%$ in the control and probiotic 
221 group, respectively; $P=0.28$ ) did not differ significantly between the control and probiotic

222 group. The number of treatments due to ileitis during the finisher phase, however, tended to be

223 lower in the probiotic group ( $7 \mathrm{vs} 16 ; P=0.07$ ). These results correspond with the results of

224 Opriessnig et al. (2019), who showed that Bacillus pumilus and to a lesser degree Bacillus

225 amyloliquefaciens and Bacillus licheniformis suppress a Lawsonia intracellularis infection.

226 Thus, a better health might also contribute to the improvement in FCR.

227 In several studies (Alexopoulos et al., 2004; Ji et al. 2013; Zentek et al., 2017), the number of 228 pigs with diarrhea was reduced when fed diets containing Bacillus amyloliquefaciens or Bacillus 229 subtilis. Kim et al. (2019), however, showed that supplementation of Bacillus subtilis did not 230 reduce the frequency of diarrhea. In our study most of the pigs had normal faecal consistency 231 during the grower phase and the mean faecal score during the grower phase was not affected by 232 probiotic supplementation. As mentioned earlier, during the finisher phase, the number of pigs 233 treated due to ileitis (pigs with diarrhea and grey-dark faeces combined with growth reduction) 234 was reduced by probiotic supplementation.

235 The effect of Bacillus subtilis was often studied in combination with other Bacillus spp.

236 Supplementation of Bacillus-based probiotics including Bacillus subtilis resulted in an improved

237 FCR in the grower phase and an improved ADFI and ADG during the finisher phase and the 238 overall fattening period (Bouwhuis et al., 2017), an improved ADG and FCR during the grower 239 phase, an impaired FCR during the finisher phase and an improved FCR during the overall 240 fattening period (Jørgensen et al., 2016), an improved FCR during the finisher phase and the 241 overall fattening period (Davis et al., 2008), an improved ADG and FCR during the grower 242 phase and the overall fattening period (Alexopoulos et al., 2004), an improved ADFI and ADG 243 during the grower phase (Wang et al., 2009) and an improved ADG during the grower phase 
244 (Chen et al., 2005) and finisher phase (Chen et al., 2006). In most of these studies a positive 245 effect of Bacillus-based probiotics including Bacillus subtilis on the performance of GF pigs was 246 found. However, in some studies no effect on the performance of GF pigs was shown. Moreover,

247 in some studies Bacillus-based probiotics improved fat digestibility (Jørgensen et al., 2016), 248 nitrogen $(\mathrm{N})$ digestibility (Chen et al., 2015) or DE of the diet (Blavi et al., 2019) in growing 249 pigs, whereas in other studies it decreased $\mathrm{N}$ digestibility (Blavi et al., 2019) in growing pigs or 250 did not affect $\mathrm{N}$ digestibility in finishing pigs (Chen et al., 2006). The different effects of

251 Bacillus based probiotics including Bacillus subtilis on performance and nutrient digestibility in 252 GF pigs may be due to several factors, like differences in diet compositions, Bacillus strains, 253 dose levels, age of the animals, sanitary status, genetics and interaction with environmental 254 factors (Jørgensen et al., 2016; Barba-Vidal et al., 2018; Mingmongkolchai and Panbangred, 255 2018).

256 Overall, our results indicate that supplementation of diets fed to GF pigs with a mix of two 257 specific strains of Bacillus amyloliquefaciens (DSM 25840) and Bacillus subtilis (DSM 32324) 258 improve the FCR and may reduce the number of veterinary treatments due to ileitis.

\section{Conclusions}

261 Feeding GF pigs diets supplemented with $400 \mathrm{mg} / \mathrm{kg}\left(6 \times 10^{8} \mathrm{CFU}\right.$ per $\mathrm{kg}$ feed $)$ of a Bacillus262 based probiotic containing a mixture of viable spores of Bacillus amyloliquefaciens (DSM 25840) 263 and Bacillus subtilis (DSM 32324) improved the feed conversion ratio of the pigs during the 264 finisher period and the overall fattening period and tended to improve the feed conversion ratio 
265 during the grower period. Moreover, it tended to decrease the number of veterinary treatments due 266 to ileitis (an infection with Lawsonia intracellularis).

\section{References}

269 Ahasan, A.S.M.L., Agazzi, A., Invernizzi, G., Bontempo, V., Savoini, G., 2015. The beneficial 270 role of probiotics in monogastric animal nutrition and health. J. Dairy, Vet. \& Anim. Res. 2, 127120.

272 Alexopoulos, C., Georgoulakis, I.E., Tzivara, A., Kyriakis, C.S., Govaris, A., Kyriakis, S.C., 2004. 273 Field evaluation of the effect of a probiotic-containing Bacillus licheniformis and Bacillus 274 subtilis spores on the health status, performance, and carcass quality of grower and finisher pigs. 275 J. Vet. Med. A 51, 306-312.

Bajagai, Y.S., Klieve, A.V., Dart, P.J., Bryden, W.L., 2016. Probiotics in animal nutrition 277 production, impact and regulation. In FAO Animal Production and Health Paper (ed. HPS 278 Makkar), 179pp. Rome, Italy.

279 Barba-Vidal, E., Martín-Orúe, S.M., Castillejos, L., 2018. Review: Are we using probiotics 280 correctly in post-weaning piglets? Anim. 12, 2489-2498.

281 Blavi, L., Jørgensen, J.N, Stein, H.H., 2019. Effects of Bacillus amyloliquefaciens and Bacillus 282 subtilis on ileal digestibility of AA and total tract digestibility of CP and gross energy in diets 283 fed to growing pigs. J. Anim. Sci. 97, 727-734.

284 Bouwhuis, M., Jørgensen, J.N., Jørgensen, L., Van der Aar, P., Molist, F., 2017. The use of 285 probiotics containing spores of Bacillus licheniformis and Bacillus subtilis or Bacillus 286 amyloliquefaciens improves the growth performance of grower-finisher pigs. Proceedings of 287 IPC2017, Budapest, Hungary (p. 20.). 
Cai, L., Indrakumar, S., Kiarie, E., Kim, I.H., 2015. Effects of a multi-strain Bacillus speciesbased direct-fed microbial on growth performance, nutrient digestibility, blood profile, and gut health in nursery pigs fed corn-soybean meal-based diets. J. Anim. Sci. 93, 4336-4342.

Centraal Veevoederbureau (CVB), 2012. CVB Table Booklet Feeding of Pigs: Feeding standards, feeding advices and nutritional values of feed ingredients of pigs. CVB-reeks nr. 50 . Productschap Diervoeder Den Haag, the Netherlands.

Chen, Y.J., Son, K.S., Min, B.J., Cho, J.H., Kwon, O.S., Kim, I.H., 2005. Effects of dietary probiotic on growth performance, nutrients digestibility, blood characteristics and fecal noxious gas content in growing pigs. Asian-Aust. J. Anim. Sci. 18, 1464-1468.

Chen, Y.J., Min, B.J., Cho, J.H., Kwon, O.S., Son, K.S., Kim, H.J., Kim, I.H., 2006. Effects of dietary bacillus-based probiotic on growth performance, nutrients digestibility, blood characteristics and fecal noxious gas content in finishing pigs. Asian-Aust. J. Anim. Sci. 19, $587-592$.

Davis, M.E., Parrott, T., Brown, D.C., de Rodas, B.Z., Johnson, Z.B., Maxwell, C.V., Rehberger, T., 2008. Effect of a Bacillus-based direct-fed microbial feed supplement on growth performance and pen cleaning characteristics of growing-finishing pigs. J. Anim. Sci. 86, 1459-1467.

European Commission, 2007. Commission Recommendation of 18 June 2007 on guidelines for the accommodation and care of animals used for experimental and other scientific purposes (notified under document number C(2007) 2525) (2007/526/EC). Off. J. Eur. Union L 197, 189, 30.7.2007.

European Commission, 2009. Commission Regulation (EC) No 152/2009 of 27 January 2009 laying down the methods of sampling and analysis for the official control of feed. Off. J. Eur. Union L 54, 1-130, 26.2.2009. 
311 European Commission, 2010. Directive 2010/63/EU of the European parliament and of the council

312 of 22 September 2010 on the protection of animals used for scientific purposes. Off. J. Eur.

313 Union 276, 33-79, 20/10/2010.

314 Gangadharan, D., Sivaramakrishnan, S., Nampoothiri, K.M., Sukumaran, R K., Pandey, A., 2008.

315 Response surface methodology for the optimization of alpha amylase production by Bacillus

316 amyloliquefaciens. Bioresour. Technol. 99, 4597-4602.

317 GenStat, 2018. GenStat for Windows $19^{\text {th }}$ Edition. VSN International Ltd., Hemel Hempstead, $318 \quad$ UK.

319 Gould, A.R., May, B.K., Elliott, W.H., 1975. Release of extracellular enzymes from Bacillus 320 amyloliquefaciens. J. Bacteriol. 122, 34-40.

321 Jaworski, N.W., Owusu-Asiedu, A., Walsh, M.C., McCann, J.C., Loor, J.J., Stein, H.H., 2017.

322 Effects of a 3 strain Bacillus-based direct-fed microbial and dietary fiber concentration on 323 growth performance and expression of genes related to absorption and metabolism of volatile 324 fatty acids in weanling pigs. J. Anim. Sci. 95, 308-319.

325 Ji J., Hu S., Zheng M., Du W., Shang Q., Li W., 2013. Bacillus amyloliquefaciens SC06 inhibits 326 ETEC-induced pro-inflammatory responses by suppression of MAPK signaling pathways in 327 IPEC-1 cells and diarrhea in weaned piglets. Livest. Sci. 158, 206-214.

328 Jørgensen, J.N, Sánchez Laguna, J., Millán, C., Casabuena, O., Gracia, M.I., 2016. Effects of a 329 Bacillus-based probiotic and dietary energy content on the performance and nutrient digestibility 330 of wean to finish pigs. Anim. Feed Sci. Technol. 221, 54-61.

331 Kim, K., He, Y., Xiong, X., Ehrlich, A., Li, X., Raybould, H., Atwill, E.R., Maga1, E.A., 332 Jørgensen, J., Liu, Y., 2019. Dietary supplementation of Bacillus subtilis influenced intestinal 
health of weaned pigs experimentally infected with a pathogenic E. coli. J. Anim. Sci. and Biotechnol. 10, 52.

Larsen, N., Thorsen, L., Kpikpi, E.N., Stuer-Lauridsen, B., Cantor, M.D., Nielsen, B., Brockmann, E., Derkx, P.M.F., Jespersen, L., 2014. Characterization of Bacillus spp. strains for use as probiotic additives in pig feed. Appl. Microbiol. Biotechnol. 98, 1105-1118.

Lee, Y.J., Kim, B.K., Lee, B.H., Jo, K.I., Lee, N.K., Chung, C.H., Lee, Y.C., Lee, J.W., 2008. Purification and characterization of cellulose produced by Bacillus amyloliquefaciens DL-3 utilizing rice hull. Bioresour. Technol. 99, 378-386.

Li, Y., Zhang, H., Chen, Y.P., Yang, M.X., Zhang, L.L., Lu, Z.X., 2015. Bacillus amyloliquefaciens supplementation alleviates immunological stress and intestinal damage in lipopolysaccharide-challenged broilers. Anim. Feed Sci. Technol. 208, 119-31.

Mingmongkolchai, S., Panbangred, W., 2018. Bacillus probiotics: an alternative to antibiotics for livestock production. J. Appl. Microbiol. 124, 1334-1346.

NEN-EN-15784, 2009. Animal feeding stuffs - Isolation and enumeration of presumptive Bacillus spp. ICS 65.120, 1-14, Nederlands Normalisatie-instituut, Delft, The Netherlands.

NEN-EN 15510, 2017. Animal feeding stuffs: Methods of sampling and analysis - Determination of calcium, sodium, phosphorus, magnesium, potassium, iron, zinc, copper, manganese, cobalt, molybdenum and lead by ICP-AES. ICS 65.120, 1-29, Koninklijk Nederlands Normalisatieinstituut, Delft, The Netherlands.

Opriessnig, T., Karuppannan, A.K., Beckler, D., Ait-Ali, T., Cubas-Atienzar, A., Halbur, P.G., 2019. Bacillus pumilus probiotic feed supplementation mitigates Lawsonia intracellularis shedding and lesions. Vet. Res., 50, 85-95.

SAS 9.3, 2011. SAS Institute Inc., Cary, NC, USA. 
356 Van Nieuwamerongen, S.E, Soede, N.M., Van der Peet-Schwering, C.M.C., Kemp, B., Bolhuis, 357 J.E., 2017. Gradual weaning during an extended lactation period improves performance and 358 behavior of pigs raised in a multi-suckling system. Appl. Anim. Behav. Sci. 194, 24-35.

359 Wang, Y., Cho, J.H., Chen, Y.J., Yoo, J.S., Huang, Y., Kim, H.J., Kim, I.H., 2009. The effect of 360 probiotic BioPlus $2 \mathrm{~B} \AA$ on growth performance, dry matter and nitrogen digestibility and slurry 361 noxious gas emission in growing pigs. Livest. Sci. 120, 35-42.

362 Zentek, J., Röhe, I., Cernat, R., Nielsen, B., 2017. Efficacy of pre-selected bacilli as probiotic feed 363 additives in F4+ Escherichia coli challenged post-weaning piglets. The 6th Beneficial Microbes 364 Conference: pre- and probiotics for lifelong human and animal health. 9-11 October, 365 Amsterdam, The Netherlands; p. 80 (Abstract). 
368 Ingredient and composition of the control diets (as-fed basis) ${ }^{\mathrm{a}}$

Grower diet

Maize

Wheat middlings

Rapeseed meal

Soybean meal

Sunflower seed meal

Palm oil

Soy oil

Limestone

Monocalcium phosphate

Sodium bicarbonate

Salt

DL-Methionine

L-Tryptophan

L-Lysine $\mathrm{HCl}$

L-Threonine

Vitamin and mineral premix

Phytase

Analysed composition

Dry matter, g/kg

Crude protein, $\mathrm{g} / \mathrm{kg}$

Crude fat, $\mathrm{g} / \mathrm{kg}$

Ash, g/kg

$\mathrm{Cu}, \mathrm{mg} / \mathrm{kg}$

Calculated analysis

Starch, g/kg

Metabolisable Energy, MJ/kg

Net Energy, MJ/kg

AID lysine ${ }^{\mathrm{b}}, \mathrm{g} / \mathrm{kg}$

$\mathrm{Ca}, \mathrm{g} / \mathrm{kg}$

$\mathrm{Cu}, \mathrm{mg} / \mathrm{kg}$

$\mathrm{Mn}, \mathrm{mg} / \mathrm{kg}$

$\mathrm{Zn}, \mathrm{mg} / \mathrm{kg}$

Vitamin A, IU/kg

Vitamin D3, IU/kg

Vitamin E, mg/kg

$\mathrm{Se}, \mathrm{mg} / \mathrm{kg}$

Choline, $\mathrm{mg} / \mathrm{kg}$
252.60

50.00

354.63

81.10

Finisher diet

252.60

100.00

297.24

50.70

50.60

$49.90 \quad 79.80$

$120.00 \quad 62.20$

$28.59 \quad 50.06$

$13.20 \quad 17.30$

$10.00 \quad 13.40$

$\begin{array}{ll}10.10 & 7.49\end{array}$

$3.39 \quad 0.50$

2.20

$\begin{array}{ll}4.52 & 4.09\end{array}$

$1.25 \quad 0.30$

0.34 -

$\begin{array}{ll}5.22 & 3.28\end{array}$

$1.99 \quad 0.87$

$6.00 \quad 5.60$
4.97

$4.97 \quad 3.98$

$903 \quad 901$

$182 \quad 167$

$43 \quad 47$

$46-40$

22

439.2

422.2

$14.33-14.33$

$10.03 \quad 10.03$

$10.1 \quad 7.8$

$6.0 \quad 4.7$

$20.6 \quad 21.0$

$50.2 \quad 56.7$

$91.6 \quad 95.7$

$6,533 \quad 6,533$

$1,608 \quad 1,608$

$80.4 \quad 74.4$

$0.2 \quad 0.2$

$22.6 \quad 45.6$ 
Vitamin B2, mg/kg $\quad 4.0 \quad 4.0$

Vitamin B5, mg/kg $\quad 9.0 \quad 9.0$

$\begin{array}{lrr}\text { Niacine, } \mathrm{mg} / \mathrm{kg} & 30.2 & 30.2\end{array}$

Vitamin B12, $\mathrm{mg} / \mathrm{kg} \quad 0.02 \quad 0.02$

370 a Diets with Bacillus-based probiotic: $400 \mathrm{mg} / \mathrm{kg}$ limestone $\left(\mathrm{CaCO}_{3}\right)$ in the control diets was 371 exchanged with $400 \mathrm{mg} / \mathrm{kg}$ of the Bacillus-based probiotic.

372 b AID lysine, apparent ileal digestible lysine.

373

374

375 
376

Table 2

378

379

380

Growth performance ${ }^{1}$ of growing-finishing pigs (average initial age $63 \pm 0.6$ days) fed a control diet or a diet containing $400 \mathrm{mg} / \mathrm{kg}$ of a Bacillus-based probiotic (a mixture of Bacillus amyloliquefaciens and Bacillus subtilis)

\begin{tabular}{lllll}
\hline & Control diet & Probiotic diet & SEM & $P$-value \\
\hline Body weight, kg & & & & \\
$\quad$ At start & 23.2 & 23.2 & 0.01 & 0.50 \\
Day 35 & 51.1 & 51.2 & 0.22 & 0.79 \\
$\quad$ Day 102 & 113.4 & 114.6 & 0.60 & 0.16 \\
Grower phase (1-35 days) & & & \\
$\quad$ ADG $^{2}$, g & 798 & 800 & 6.2 & 0.82 \\
ADFI $^{2}, \mathrm{~kg}$ & 1.41 & 1.40 & 0.011 & 0.33 \\
FCR $^{2}$ & 1.77 & 1.75 & 0.009 & 0.09 \\
Finisher phase (36-102 days) & & & & \\
ADG, g & 930 & 948 & 6.9 & 0.09 \\
ADFI, kg & 2.26 & 2.26 & 0.016 & 0.92 \\
FCR & 2.43 & 2.39 & 0.014 & 0.03 \\
Overall (1-102 days) & & & & \\
ADG, g & 885 & 897 & 5.8 & 0.15 \\
ADFI, kg & 1.97 & 1.96 & 0.013 & 0.73 \\
FCR & 2.22 & 2.19 & 0.010 & 0.01 \\
\hline
\end{tabular}

1 Data represents LSmeans based on 24 replicates (pen is the experimental unit) in the control group and 23 replicates (pen is the experimental unit) in the probiotic group. In the probiotic 383 group, one pen was regarded as an outlier.

${ }^{2}$ ADG, average daily gain; ADFI, average daily feed intake; FCR, feed conversion ratio. 
Table 3

388 Health and faecal scores of growing-finishing pigs fed a control diet or a diet containing $400 \mathrm{mg} / \mathrm{kg}$

\begin{tabular}{|c|c|c|c|c|}
\hline & Control diet & Probiotic diet & SEM & $P$-value \\
\hline No of pig at start & 288 & 276 & & \\
\hline Culled pigs, $\%$ & 3.1 & 2.5 & - & 0.67 \\
\hline Number of pigs treated with antibiotics & 33 & 24 & - & 0.28 \\
\hline Number of treatments with antibiotics ${ }^{\mathrm{a}}$ & 38 & 25 & - & 0.12 \\
\hline \multicolumn{5}{|l|}{ Reason of treatment: } \\
\hline Ileitis ${ }^{b}$ & 16 & 7 & - & 0.07 \\
\hline Lameness & 17 & 15 & - & 0.81 \\
\hline Other reasons & 5 & 3 & - & 0.60 \\
\hline $\begin{array}{l}\text { Antibiotic treatment days } \mathrm{c}, \% \text { of total } \\
\text { number of trial days }\end{array}$ & 0.36 & 0.30 & - & 0.18 \\
\hline Pen faecal score $^{\mathrm{d}}$ & 0.020 & 0.018 & 0.0036 & 0.71 \\
\hline
\end{tabular}

a Three pigs in the control group were treated two times and one pig was treated three times during the experimental period of 102 days. In the probiotic group one pig was treated two times.

b All treatments due to ileitis were executed during the finisher phase.

c In general, pigs were treated for 3-5 consecutive days per treatment.

d Recorded weekly during the starter phase $(5$ weeks): normal faeces $($ score $=0)$, pasty faeces $($ score $=1)$, watery faeces $($ score $=2)$. 